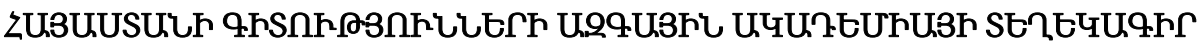 ИЗВЕСТИЯ НАЦИОНАЛЬНОЙ АКАДЕМИИ НАУК АРМЕНИИ
}

Uthuuquhu

72, №2, 2019

Механика

УДК 517.934

Doi- http://doi.org/10.33018/72.2.7

\section{A PROBLEM OF OPTIMAL STABILIZATION OF A QUADCOPTER UAV FLIGHT Shahinyan A.S.}

Keywords: Dynamical Systems, Optimal Control, Optimal Stabilization, Quadcopter UAV.

Шагинян А. С

Об одной задаче оптимальной стабилизации полёта квадрокоптера

Ключевые слова: Динамические системы, оптимальное управление, оптимальная стабилизация, квадрокоптер БЛА.

В работе рассматривается задача оптимальной стабилизации безпилотного летательного аппарата (квадрокоптера) в линейном приближении. Приведена система дифференциальных уравнений, опысивающая динамика вадрокоптера, проверена полная управляемость линейного приближения полученной управляемой системы, поставлена и решена задача оптимальной стабилизации этой системы методом Ляпунова-Беллмана. Получены оптимальная функция Ляпунова, оптимальные управляющие воздействия. Построены графики оптимальных управлений и оптимальных движений.

Zuhhijuiu U.U.

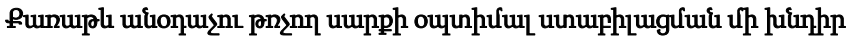

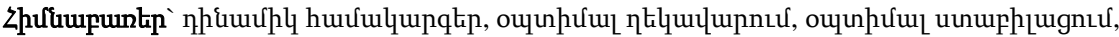
punuple U.OU:

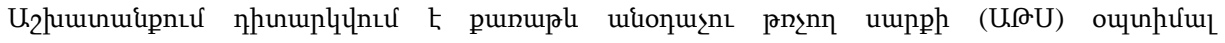

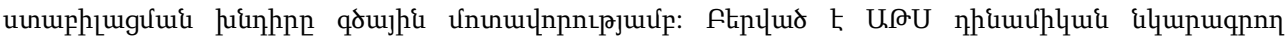

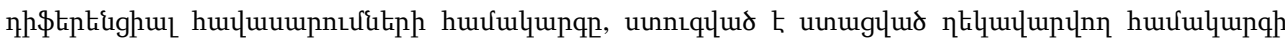

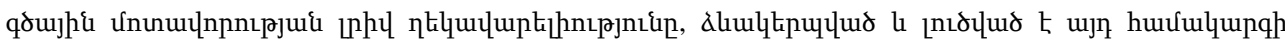

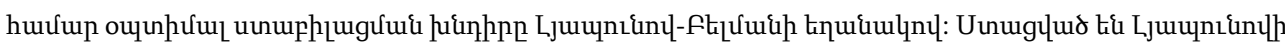

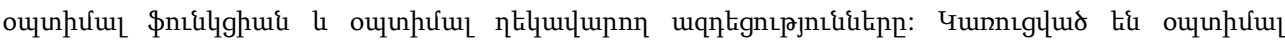

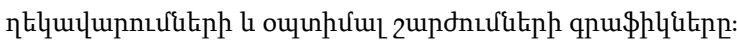

This paper discusses an optimal stabilization problem of a quadcopter unmanned aerial vehicle (UAV). The dynamics of the UAV is presented and the linear time invariant (LTI) model of it is considered. The controllability of the LTI model is checked and an optimal stability problem is defined and solved for the LTI system using Lyapunov-Bellman method. The Lyapunov optimal function and optimal control inputs are gained. The graphs of optimal control inputs and optimal trajectories are constructed and presented.

1. Introduction: In this paper we are going to discuss a stabilization problem of a quadcopter (also called a quadrotor) unmanned aerial vehicle (UAV). A quadcopter is a helicopter equipped with four engines each of which have a propeller attached. Quadcopters are of high interest among researchers because of their simple structure. Moreover, quadcopters are agile and maneuverable which makes it easy to experiment complex control algorithms using them. 
There are several papers which study the stabilization problem of quadcopters while approaching the problem from different view angles. Some papers use PID controllers, others do the job using just PD controllers, some researchers solved the problem using LQR regulator method. A short description of such papers is given in [1].

In [2] an Optimal Control problem is stated and solved for the linearized model. A numerical example is also given by presenting optimal control inputs calculated analytically and optimal trajectories of the motion.

Here in this paper we are going to approach the problem using so called Lyapunov-Bellman method. Using this method for Linear Time Invariant (LTI) systems we can find a Lyapunov optimal function, optimal control inputs and optimal trajectories.

What follows the introduction are three sections which are modelling of the system, problem definition and solution and discussion of results. The discussed system is a quadcopter, and the model is derived theoretically. Then the problem is defined and solved. The results are discussed by providing some simulations results and comments.

2. Model of the System: To derive the pure theoretical dynamics of a UAV let us fix a coordinate system $O x y z$. Let $O$ be the origin. We will also need another coordinate system $O_{B} x_{B} y_{B} z_{B}$ fixed in the center of mass $O_{B}$ of the UAV (fig.1). The torques and forces generated by each of the propellers are shown in the Figure 1. The propellers are numbered 1 to 4 [1].
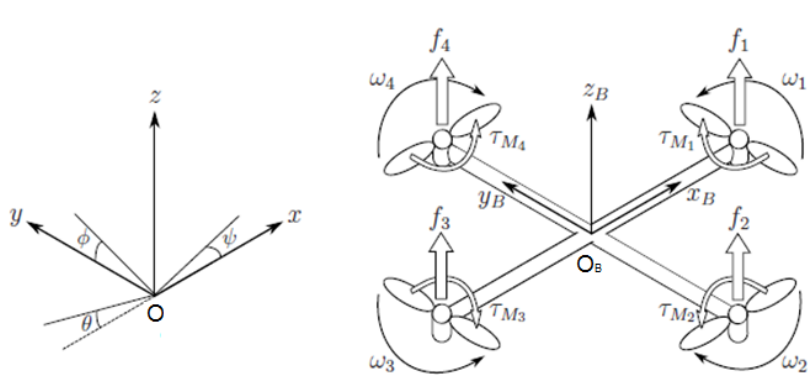

Let $\xi=\left(\begin{array}{lll}x & y & z\end{array}\right)^{T}$ be the coordinates of the center of mass of the UAV with respect to the system Oxyz. As mentioned above, the center of the mass of the UAV coincides with the origin of the coordinate system $O_{B} x_{B} y_{B} z_{B}$.

Figure 1.

Let us describe the inclined position of the UAV about the point $O_{B}$ using yaw, pitch and roll angles. Let $\Phi$ be the pitch angle, $\Theta$ be the roll angle and, finally, let $\Psi$ be the yaw angle. Then we will have two vectors describing the position of the UAV. Those are the following:

$$
\xi=\left(\begin{array}{lll}
x & y & z
\end{array}\right)^{T}, \quad \eta=\left(\begin{array}{lll}
\Phi & \Theta & \Psi
\end{array}\right)^{T}
$$

In the coordinate system the linear velocities $V_{B}$ and the angular velocities $v$ are the following

$V_{B}=\left(\begin{array}{lll}V_{B x} & V_{B y} & V_{B z}\end{array}\right)^{T}, \quad v=\left(\begin{array}{lll}p & q & r\end{array}\right)^{T}$

In this setup we will have the dynamics of the system as given below $[1 ; 3]$.

$\ddot{x}=\frac{T}{m} c_{\Psi} s_{\Theta} c_{\Phi}+\frac{T}{m} s_{\Psi} s_{\Phi}, \quad \ddot{y}=\frac{T}{m} s_{\Psi} s_{\Theta} c_{\Phi}-\frac{T}{m} c_{\Psi} s_{\Phi}, \quad \ddot{z}=-g+\frac{T}{m} c_{\Theta} c_{\Phi}$, 


$$
\begin{aligned}
& \dot{\Phi}=p+\frac{s_{\Phi} s_{\Theta}}{c_{\Theta}} q+\frac{c_{\Phi} s_{\Theta}}{c_{\Theta}} r, \dot{\Theta}=c_{\Phi} q-s_{\Phi} r, \dot{\Psi}=\frac{s_{\Phi}}{c_{\Theta}} q+\frac{c_{\Phi}}{c_{\Theta}} r, \\
& \dot{p}=\frac{\left(I_{y y}-I_{z z}\right) q r}{I_{x x}}-I_{r} \frac{q}{I_{x x}} \omega_{\Gamma}+\frac{\tau_{\Phi}}{I_{x x}}, \\
& \dot{q}=\frac{\left(I_{z z}-I_{x x}\right) p r}{I_{y y}}-I_{r} \frac{p}{I_{y y}} \omega_{\Gamma}+\frac{\tau_{\Theta}}{I_{y y}}, \\
& \dot{r}=\frac{\left(I_{x x}-I_{y y}\right) p q}{I_{z z}}-I_{r} \frac{q}{I_{z z}} \omega_{\Gamma}+\frac{\tau_{\Psi}}{I_{z z}} .
\end{aligned}
$$

Where the following notations are used: $C_{\alpha}:=\cos \alpha, S_{\alpha}:=\sin \alpha$,

$$
\tau_{B}=\left(\begin{array}{c}
\tau_{\Phi} \\
\tau_{\Theta} \\
\tau_{\Psi}
\end{array}\right)=\left(\begin{array}{c}
l k\left(-\omega_{2}^{2}+\omega_{4}^{2}\right) \\
l k\left(-\omega_{1}^{2}+\omega_{3}^{2}\right) \\
\sum_{i} \tau_{i}
\end{array}\right) \text { and } T=\sum_{i} F_{i}=\sum_{i} k \omega_{i}^{2}, \quad \vec{T}=\left(\begin{array}{lll}
0 & 0 & T
\end{array}\right)^{T}
$$

Let us do the following notations and linearize the system around the origin.

$x_{1}=x, x_{2}=\dot{x}, x_{3}=y, x_{4}=\dot{y}, x_{5}=z, x_{6}=\dot{z}$,

$x_{7}=\Phi, x_{8}=\Theta, x_{9}=\Psi, x_{10}=p, x_{11}=q, x_{12}=r$

We will have

$\dot{x}_{1}=x_{2}, \dot{x}_{2}=g x_{8}, \dot{x}_{3}=x_{4}, \dot{x}_{4}=-g x_{7}, \dot{x}_{5}=x_{6}, \dot{x}_{6}=u_{1}$

$\dot{x}_{7}=x_{10}, \dot{x}_{8}=x_{11}, \dot{x}_{9}=x_{12}, \dot{x}_{10}=\frac{u_{2}}{I_{x x}}, \dot{x}_{11}=\frac{u_{3}}{I_{y y}}, \dot{x}_{12}=\frac{u_{4}}{I_{z z}}$

Where $u_{1}=\frac{T}{m}-g, u_{2}=\tau_{\Phi}, u_{3}=\tau_{\Theta}, u_{4}=\tau_{\Psi}$

In [2] it is discussed and shown that the system (5) is fully controllable.

3. Stabilization Problem: Let us now define the stabilization problem that we want to solve.

Problem: Given the system (1.8), the initial position of the system $x(0)=x_{0}$, find control inputs $u^{0}=\left(\begin{array}{llll}u_{1}^{0} & u_{2}^{0} & u_{3}^{0} & u_{4}^{0}\end{array}\right)^{T}$ such that it drives the system from the given initial position to asymptotically stable state, while minimizing the given linear quadratic regulator

$$
J[\bullet]=\int_{0}^{\infty}\left(\sum_{i=1}^{12} x_{i}^{2}+\sum_{i=1}^{4} u_{i}^{2}\right) d \tau .
$$

Solution: We will follow Lyapunov-Bellman method to solve this problem. Notice that the system (5) can be decomposed into 4 systems which are the following. 
$\dot{x}_{1}=x_{2}, \dot{x}_{2}=g x_{8}, \dot{x}_{8}=x_{11}, \dot{x}_{11}=\frac{u_{3}}{I_{y y}}$

$\dot{x}_{3}=x_{4}, \dot{x}_{4}=-g x_{7}, \dot{x}_{7}=x_{10}, \dot{x}_{10}=\frac{u_{2}}{I_{x x}}$

$\dot{x}_{5}=x_{6}, \dot{x}_{6}=u_{1}$

$\dot{x}_{9}=x_{12}, \dot{x}_{12}=\frac{u_{4}}{I_{z z}}$

So, we will have 4 independent systems which are fully controllable. This means we can solve the problem for each of these systems separately. In this case (6) will be written as

$$
J[\bullet]=J_{1}[\bullet]+J_{2}[\bullet]+J_{3}[\bullet]+J_{4}[\bullet]
$$

where

$$
\begin{aligned}
& J_{1}[\bullet]=\int_{0}^{\infty}\left(x_{5}^{2}+x_{6}^{2}+u_{1}^{2}\right) d \tau, \quad J_{2}[\bullet]=\int_{0}^{\infty}\left(x_{3}^{2}+x_{4}^{2}+x_{7}^{2}+x_{10}^{2}+u_{2}^{2}\right) d \tau, \\
& J_{3}[\bullet]=\int_{0}^{\infty}\left(x_{1}^{2}+x_{2}^{2}+x_{8}^{2}+x_{11}^{2}+u_{3}^{2}\right) d \tau, \quad J_{4}[\bullet]=\int_{0}^{\infty}\left(x_{9}^{2}+x_{12}^{2}+u_{4}^{2}\right) d \tau .
\end{aligned}
$$

As we see that system (5) can be divided into four subsystems then it is convenient to search for a Lyapunov function in the form

$$
\begin{aligned}
V\left(x_{1}, \ldots, x_{12}\right) & =V_{1}\left(x_{5}, x_{6}\right)+V_{2}\left(x_{3}, x_{4}, x_{7}, x_{10}\right)+ \\
& +V_{3}\left(x_{1}, x_{2}, x_{8}, x_{11}\right)+V_{4}\left(x_{9}, x_{12}\right)
\end{aligned}
$$

We will show the steps for one of the above subsystems (say (7)) and will present the solutions of other three systems instantly.

So, for (7) Bellman equation will be as follows.

$\mathfrak{B}[\bullet]=\frac{\partial V_{3}}{\partial x_{1}} x_{2}+\frac{\partial V_{3}}{\partial x_{2}} g x_{8}+\frac{\partial V_{3}}{\partial x_{8}} x_{11}+\frac{\partial V_{3}}{\partial x_{11}} a u_{3}+x_{1}^{2}+x_{2}^{2}+x_{8}^{2}+x_{11}^{2}+u_{3}^{2}$

Where $a=\frac{1}{I_{x x}}=\frac{1}{I_{y y}}$. Now differentiating (11) and making it equal to 0 we get that

$u_{3}^{0}=-\frac{1}{2} a \frac{\partial V_{3}}{\partial x_{11}}$

Then we will have

$\mathfrak{B}\left[\left.\bullet\right|_{u_{3}=u_{3}^{0}}=\frac{\partial V_{3}}{\partial x_{1}} x_{2}+\frac{\partial V_{3}}{\partial x_{2}} g x_{8}+\frac{\partial V_{3}}{\partial x_{8}} x_{11}-\frac{1}{4} a^{2}\left(\frac{\partial V_{3}}{\partial x_{11}}\right)^{2}+x_{1}^{2}+x_{2}^{2}+x_{8}^{2}+x_{11}^{2}=0\right.$

We are looking for Lyapunov function in the form shown below.

$$
\begin{aligned}
V_{3}\left(x_{1}, x_{2}, x_{8}, x_{11}\right) & =\frac{1}{2}\left(c_{11} x_{1}^{2}+c_{22} x_{2}^{2}+c_{88} x_{8}^{2}+c_{111} x_{11}^{2}+2 c_{12} x_{1} x_{2}+2 c_{18} x_{1} x_{8}+\right. \\
& \left.+2 c_{111} x_{1} x_{11}+2 c_{28} x_{2} x_{8}+2 c_{211} x_{2} x_{11}+2 c_{811} x_{8} x_{11}\right)
\end{aligned}
$$

Substituting (14) into (13) leads us to following equation. 


$$
\begin{aligned}
& \left(c_{11} x_{1}+c_{12} x_{2}+c_{18} x_{8}+c_{111} x_{11}\right) x_{2}+\left(c_{12} x_{1}+c_{22} x_{2}+c_{28} x_{8}+c_{211} x_{11}\right) g x_{8}+ \\
& +\left(c_{18} x_{1}+c_{28} x_{2}+c_{88} x_{8}+c_{811} x_{11}\right) x_{11}-\frac{1}{4} a^{2}\left(c_{111} x_{1}+c_{211} x_{2}+c_{811} x_{8}+c_{111} x_{11}\right)^{2}+ \\
& +x_{1}^{2}+x_{2}^{2}+x_{8}^{2}+x_{11}^{2}=0
\end{aligned}
$$

Because the coefficients of polynomials in opposite sides of an equity must be equal, then from (15) it simply follows that

$$
\begin{aligned}
& -\frac{1}{4} a^{2} c_{111}^{2}+1=0,-\frac{1}{4} a^{2} c_{211}^{2}+c_{12}+1=0, \\
& -\frac{1}{4} a^{2} c_{811}^{2}+g c_{28}+1=0,-\frac{1}{4} a^{2} c_{1111}^{2}+c_{811}+1=0, \\
& -\frac{1}{2} a^{2} c_{111} c_{211}+c_{11}=0,-\frac{1}{2} a^{2} c_{111} c_{811}+g c_{12}=0, \\
& -\frac{1}{2} a^{2} c_{111} c_{1111}+c_{18}=0,-\frac{1}{2} a^{2} c_{211} c_{811}+c_{18}+g c_{22}=0, \\
& -\frac{1}{2} a^{2} c_{211} c_{1111}+c_{111}+c_{28}=0,-\frac{1}{2} a^{2} c_{811} c_{1111}+g c_{211}+c_{88}=0
\end{aligned}
$$

Here the parameters have the values $a=205.93, g=9.81$. The solution of (16) that makes $V_{3}(x)$ a positive definite function is the following:

$c_{11}=2.912, c_{22}=1.423, c_{88}=11.148, c_{1111}=0.00997, c_{12}=1.121$

$c_{18}=2.053, c_{111}=0.00971, c_{28}=2.979, c_{211}=0.0141, c_{811}=0.0534$

It only remains to substitute values from (17) into (14) and then substitute into (12). Thus, we will have $u_{3}^{0}$.

By doing the same steps we will get also $V_{1}, V_{2}, V_{4}$ and $u_{1}^{0}, u_{2}^{0}, u_{4}^{0}$. For $V_{1}, V_{2}, V_{3}, V_{4}$ we will have.

$$
\begin{aligned}
& V_{1}\left(x_{5}, x_{6}\right)=1.732 x_{5}^{2}+2 x_{5} x_{6}+1.732 x_{6}^{2} \\
& V_{2}\left(x_{3}, x_{4}, x_{7}, x_{10}\right)=1.457 \mathrm{x}_{3}^{2}+0.712 \mathrm{x}_{4}^{2}+5.574 \mathrm{x}_{7}^{2}+0.00499 \mathrm{x}_{10}^{2}+1.121 x_{3} x_{4}- \\
& -2.053 x_{3} x_{7}-0.00971 x_{3} x_{10}-2.979 x_{4} x_{7}-0.0141 x_{4} x_{10}+0.0534 x_{7} x_{10} \\
& V_{3}\left(x_{1}, x_{2}, x_{8}, x_{11}\right)=1.457 \mathrm{x}_{3}^{2}+0.712 \mathrm{x}_{4}^{2}+5.574 \mathrm{x}_{7}^{2}+0.00499 \mathrm{x}_{10}^{2}+1.121 x_{3} x_{4}+ \\
& +2.053 x_{3} x_{7}+0.00971 x_{3} x_{10}+2.979 x_{4} x_{7}+0.0141 x_{4} x_{10}+0.0534 x_{7} x_{10} \\
& V_{4}\left(x_{9}, x_{12}\right)=1.009 x_{9}^{2}+0.0176 x_{9} x_{12}+0.0089 x_{12}^{2}
\end{aligned}
$$

Hence, optimal control inputs will be:

$$
\begin{aligned}
& u_{1}^{0}=-\frac{1}{2} \frac{\partial V_{1}}{\partial x_{6}}=-x_{5}-1.732 x_{6}, u_{2}^{0}=-\frac{1}{2} a \frac{\partial V_{2}}{\partial x_{10}}=1.00082 x_{3}+1.452 x_{4}-5.498 x_{7}-1.0276 x_{10} \\
& u_{3}^{0}=-\frac{1}{2} a \frac{\partial V_{3}}{\partial x_{11}}=-1.00082 x_{1}-1.452 x_{2}-5.498 x_{8}-1.0276 x_{11}, u_{4}^{0}=-\frac{1}{2} b \frac{\partial V_{4}}{\partial x_{12}}=-x_{9}-1.0112 x_{12}
\end{aligned}
$$

Where $b=\frac{1}{I_{z z}}=113.62$. And Lyapunov function for the system (5) will be the sum of Lyapunov functions of subsystems (7) -(10). That is $V^{0}\left(x_{1}, \ldots, x_{12}\right)=V_{1}^{0}\left(x_{5}, x_{6}\right)+V_{2}^{0}\left(x_{3}, x_{4}, x_{7}, x_{10}\right)+V_{3}^{0}\left(x_{1}, x_{2}, x_{8}, x_{11}\right)+V_{4}^{0}\left(x_{9}, x_{12}\right)$ 
And the minimal value of (6) is [5]

$J^{0}[\bullet]=V^{0}\left(x_{1,0}, \ldots, x_{12,0}\right)$

Where $x_{i, 0}=x_{i}(0), i=1, \ldots, 12$.

4. Discussion of Results: To visualize the results, we did some simulations. To do this, we simply substituted the optimal control inputs into the system (5) and get a system of first order ordinary differential equations. By solving that system, we will get the analytic forms of optimal trajectories. It is not convenient to show them in the paper because of their enormous sizes. The initial conditions and values of the parameters are assumed to be the following:

$x_{1,0}=50, x_{2,0}=0, x_{3,0}=30, x_{4,0}=0, x_{5,0}=10, x_{6,0}=0, x_{7,0}=0, x_{8,0}=0$,

$x_{9,0}=\frac{\pi}{2}, x_{10,0}=0, x_{11,0}=0, x_{12,0}=0, a=\frac{1000}{4.856}, b=\frac{1000}{8.801}$

So, for these initial conditions we will have our constraint optimal value equal to $J^{0}[\bullet]=8766.99$. The trajectories of states will have the form given below. The results of the simulation are presented below by presenting some of the graphs of optimal trajectories numbered as Fig.2 to Fig.5.

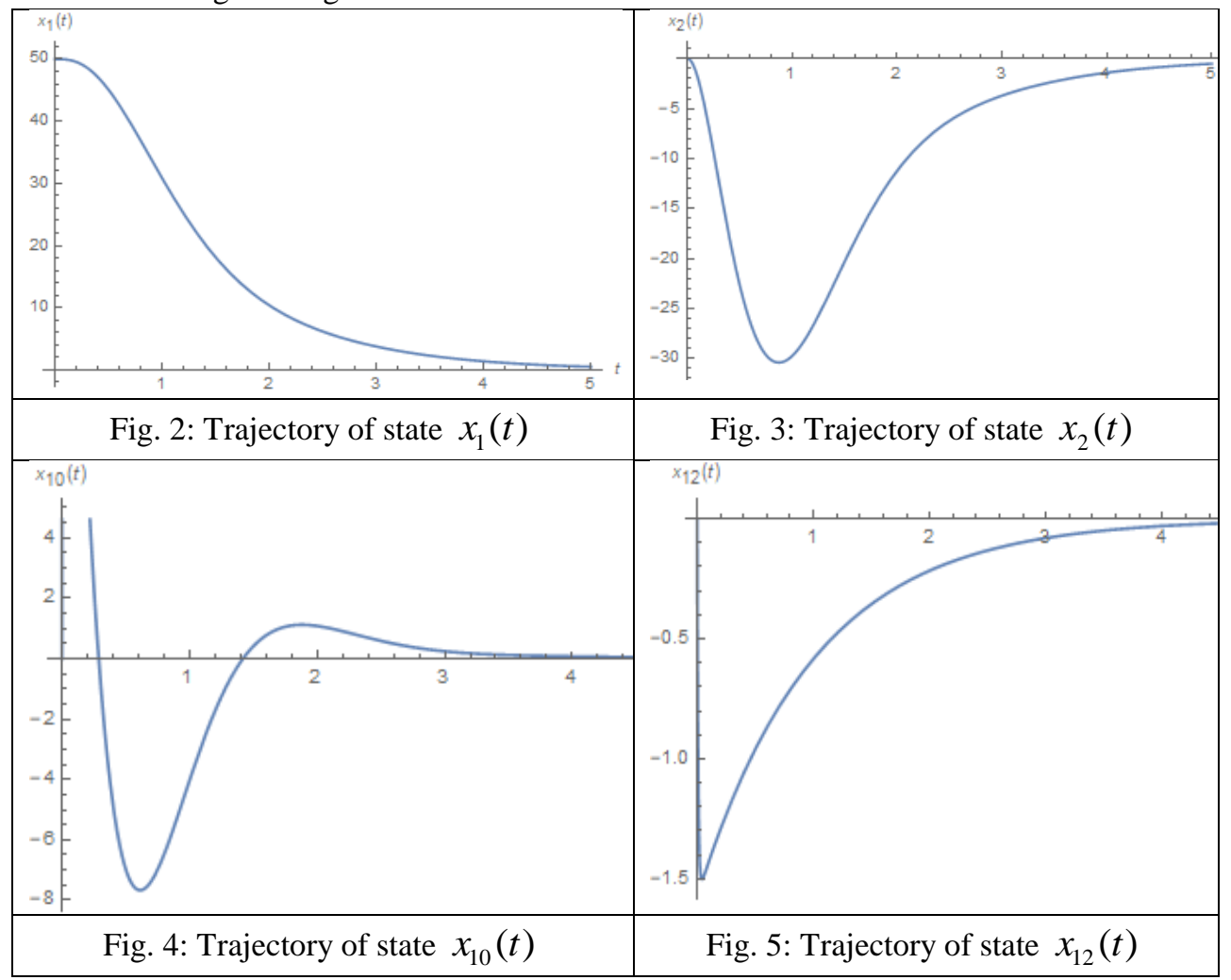




\section{Conclusion}

The problem discussed in this paper is solved using Lyapunov-Bellman method. Lyapunov Optimal function is acquired, and the optimal control inputs are constructed. Using those results we also constructed the optimal trajectories of UAV including both geometrical coordinates and their velocities. Also, the optimal value of the energy constraint is calculated and given in discussion of results section. The results are then discussed by simulating them in MATLAB R2018a. Finally, the simulation results are shown in form of graphs.

\section{REFERENCES}

1. Luukkonen T. Modelling and Control of Quadcopter. School of Science, Mat-2.4108, Independent Research project in applied mathematics, Espoo, August 22, 2011, 26 p.

2. Shahinyan A.S. An Optimal Control Problem with Energy Constraint for an Unmanned Aerial Vehicle, IX international conference The Problems of Interaction of Deformable Media, Dedicated to the $75^{\text {th }}$ anniversary of NAS RA, October 1-6, 2018, Goris.

3. Бухгольц Н.Н. Основной курс теоретической механики. М.: Наука, 1972, ч.2. 332c. Buchholz N.N. The Main Course of Theoretical Mechanics. M.: Nauka 1972, h.2. 332p. [in Russian]

4. Красовский Н.Н. Теория управления движением. М.: Наука, 1968. 476с. Krasovskii N. N. Control Theory of Motion. M.: Nauka, 1968, 476 p. [in Russian]

5. Альбрехт Э.Г., Шелементьев Г.С. Лекции по теории стабилизации. Свердловск: 1972. 274c. Al'brekht, E.G., Shelement'ev G.S., Lectures on the Stabilization Theory, Sverdlovsk, 1972, 274p. [in Russian]

6. Красовский Н.Н. Проблемы стабилизации управляемых движений. В книге Малкин И.Г. Теория устойчивости движения. Доп. 4. М.: Наука, 1966, с.475-514. Krasovskii N.N. «Stabilization Problems of Controlled Motions», In the I.G. Malkin's book; Stability Theory of Motion, Add. 4. M.: Nauka, pp. 475-517, 1966. [in Russin]

\section{Сведения об авторе:}

Шагинян Арман Смбатович - магистрант кафедры механики, Ереванский государственный университет, факультет математики и механики, (374 55) 66-37-41; E-mail: armanshah1995@gmail.com 